\title{
Stability in a One-Predator-Three-Prey Community
}

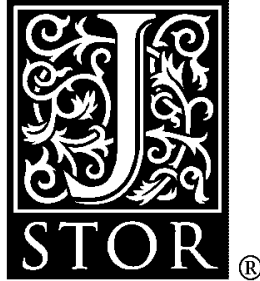

\author{
Roger A. Powell
}

The American Naturalist, Vol. 115, No. 4. (Apr., 1980), pp. 567-579.

Stable URL:

http://links.jstor.org/sici?sici=0003-0147\%28198004\%29115\%3A4\%3C567\%3ASIAOC\%3E2.0.CO\%3B2-E

The American Naturalist is currently published by The University of Chicago Press.

Your use of the JSTOR archive indicates your acceptance of JSTOR's Terms and Conditions of Use, available at

http://www.jstor.org/about/terms.html. JSTOR's Terms and Conditions of Use provides, in part, that unless you have obtained prior permission, you may not download an entire issue of a journal or multiple copies of articles, and you may use content in the JSTOR archive only for your personal, non-commercial use.

Please contact the publisher regarding any further use of this work. Publisher contact information may be obtained at http://www.jstor.org/journals/ucpress.html.

Each copy of any part of a JSTOR transmission must contain the same copyright notice that appears on the screen or printed page of such transmission.

The JSTOR Archive is a trusted digital repository providing for long-term preservation and access to leading academic journals and scholarly literature from around the world. The Archive is supported by libraries, scholarly societies, publishers, and foundations. It is an initiative of JSTOR, a not-for-profit organization with a mission to help the scholarly community take advantage of advances in technology. For more information regarding JSTOR, please contact support@jstor.org. 


\title{
STABILITY IN A ONE-PREDATOR-THREE-PREY COMMUNITY
}

\author{
Roger A. Powell* \\ Department of Biology, University of Chicago, 1103 East 57th Street, Chicago, Illinois 60637
}

Submitted January 27, 1978; Accepted October 6, 1978

May (1973) showed that the popular, general concept that "complexity implies stability" is not necessarily true for model ecosystems. Unless special limits are placed on model ecosystems, complexity as a rule implies instability. This has led many ecologists to question whether complexity enhances stability in real ecosystems. McNaughton (1977) believed that many ecologists are reluctant to challenge hypotheses generated from complex mathematical models such as those presented by May (1973). May, however, notes that real, complex ecosystems do appear to be stable. Therefore research should seek to elucidate what kinds of complexities are stabilizing.

I studied the fisher-porcupine (Martes pennanti, Erethizon dorsatum) community in Ottawa National Forest (ONF), Upper Peninsula Michigan. To investigate the stability of this real predator-prey community and the stability of some general one-predator-one-prey and one-predator-three-prey communities, I have looked at five model predator-prey communities and their stability. Five models were investigated to provide a broad base so that conclusions could be drawn from consistencies among the models. This work gives insight into whether the real predator-prey community is stable and what natural relationships between species might lead to stability.

The fisher-porcupine system is a good system to model in order to test for stability, and given stability to examine for stabilizing factors. Fishers and porcupines have coexisted at least since the Pleistocene (Anderson 1970; Hibbard 1970). This suggests that the fisher-porcupine system is stable, but periods of local extinction and reimmigration are also consistent with the fossil and subfossil record. The porcupine in ONF has only one major predator, the fisher; but the fisher has at least two alternative prey: the snowshoe hare, Lepus americanus, and deer carrion, Odocoileus virginianus (Powell 1978).

Fishers were exterminated from Upper Peninsula Michigan during the first quarter of this century due to overtrapping and habitat destruction from logging (Brander and Books 1973). Fishers were reintroduced to ONF from 1961 to 1963 (Brander and Books 1973; Irvine et al. 1962, 1964) and have subsequently become

\footnotetext{
* Present address: Departments of Zoology and Forestry, North Carolina State University, P.O. Box 5577, Raleigh, North Carolina 27650.
} 


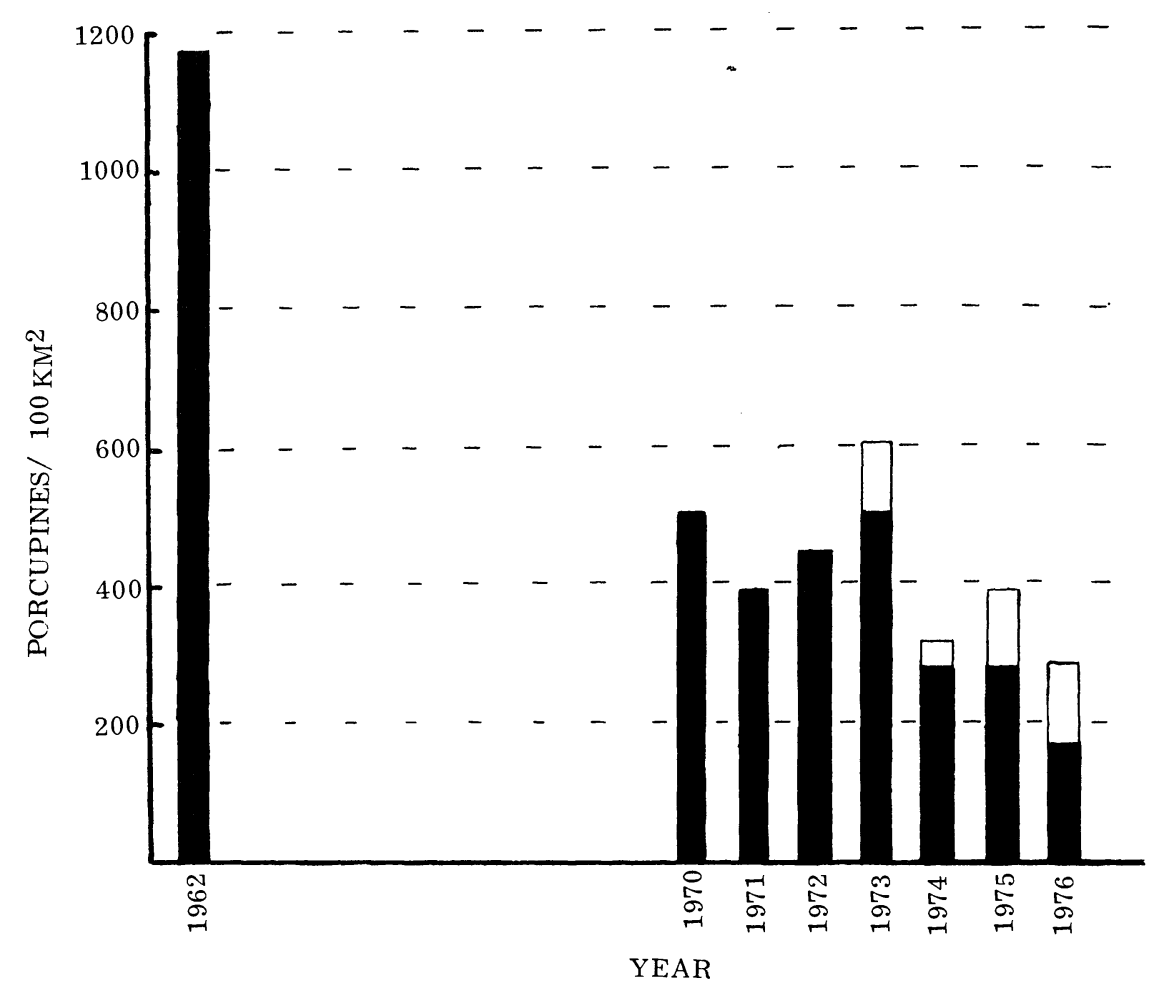

FIg. 1.-Porcupine population sizes from 1962 through 1976 on a sample study area (1.79 $\mathrm{km}^{2}$ ) in Ottawa National Forest, Upper Peninsula Michigan, converted to porcupines/100 $\mathrm{km}^{2}$. Data are taken from Powell and Brander (1977) and Brander (unpublished data for 1976). The open bars for 1973-1976 are population sizes on an enlarged census area $\left(2.83 \mathrm{~km}^{2}\right)$ encompassing the original census area.

established (Brander and Books 1973; Irvine and Brander 1971; Powell 1976; Powell and Brander 1977). The porcupine population was apparently at its carrying capacity at the time of the fisher reintroduction. Since then, the porcupine population in a sample study area has declined remarkably as a result of fisher predation (figure 1; Brander and Books 1973; Powell and Brander 1977; R. B. Brander, unpublished data). Because complex model ecosystems tend to be unstable (May 1973), and because the porcupine population in ONF has so markedly decreased in size, it is possible that a predator-prey community including fishers, porcupines, snowshoe hares, and deer carrion might be unstable, and that porcupines, fishers, or both could become locally extinct in ONF in the not too distant future.

\section{METHODS}

Five deterministic difference equation models with 1-yr intervals were derived for one-predator-one-prey communities. These models were then changed to 
one-predator-three-prey communities. Community matrices were used to test for stability in the neighborhood of the equilibrium points (one-prey) or stable cycles (three-prey) for the model communities. Then all model communities were investigated for global stability over a broad range of population densities and for sensitivity to changes in parameter values in the models using computer simulation on a WANG 720C. Use of difference equations is justifiable because fishers and porcupines reproduce only once a year, and yearlings are reproductively active (May 1973).

The simulations were run for populations per $100 \mathrm{~km}^{2}$. One-quarter of the area was snowshoe hare habitat (similar to the fisher habitat studied in ONF; see Powell 1977, 1978). Hare population density extremes were taken from Green and Evans $(1940 a, 1940 b, 1940 c)$. Porcupine carrying capacity was calculated from Brander and Books (1973) and Powell and Brander (1977). Maximum predation rate in models 3,4, and 5 was assumed to be 5-10 times fisher requirements (see Powell 1977, 1979). The communities were judged unstable if the porcupine population dropped below 1 or the fisher population dropped below 0.5 (populations which imply extinction in the real world) within $100 \mathrm{yr}$. Values for all other parameters in the models were calculated from natural history and from behavior and energetics studies described elsewhere (Powell 1977, 1978, 1979).

\section{THE MODELS}

In one-predator-one-prey models, population size for the prey species (porcupines) at time $t$ is denoted $V(t)$; that of the predator (fishers) is $P(t)$. The term representing reproduction of the prey behaves, near equilibrium, like the logistic equation for population growth. Symbols in the models are defined in table 1.

Model 1.-

$$
\begin{aligned}
& V(t+1)=V(t)\left[1+a-\frac{a V(t)}{K}\right]-\frac{h P(t)}{j}[j V(t)], \\
& P(t+1)=P(t)[1-d+c j V(t)] .
\end{aligned}
$$

This is analogous to the Lotka-Volterra model for predator-prey interactions. Prey mortality and predator reproduction are modeled proportional to kilocalories available in the prey population.

Model 2.-

$$
\begin{aligned}
& V(t+1)=V(t)\left[1+a-\frac{a V(t)}{K}\right]-\frac{w P(t)}{j}[j V(t)]^{1 / 2}, \\
& P(t+1)=P(t)\left[1+r-\frac{r P(t)}{b j V(t)}\right] .
\end{aligned}
$$

Prey mortality in this model is taken from Gause (1934) with the consideration that the exponent might be other than $\frac{1}{2}$ (Rosenzweig 1971). Predator rate of increase is modeled as logistic with a carrying capacity proportional to the kilocalories in the prey population (adapted from Leslie 1948). 
TABLE 1

Symbols Used in Models 1-5

\begin{tabular}{|c|c|}
\hline$a_{i}$ & Per capita reproduction rate of prey species $i$ \\
\hline$b$ & $\begin{array}{l}\text { Proportionality constant converting kcal of prey into fisher carrying capacity in } \\
\text { models } 2 \text { and } 3\end{array}$ \\
\hline$c$ & Fisher ability to turn kcal of prey into more fishers in model 1 \\
\hline$d$ & Fisher death rate in model 1 \\
\hline$D$ & $\begin{array}{l}\mathrm{kcal} \text { of prey a fisher can handle during the time spent to catch } 1 \mathrm{kcal} \text { of prey when kcal } \\
\text { of prey are at unit density }\end{array}$ \\
\hline .. & $\begin{array}{l}\text { An integer from } 0 \text { to } 9 \text {, inclusive, which determines the phase of the snowshoe hare } \\
\text { population cycle }\end{array}$ \\
\hline$h$ & Measure of fisher ability to capture kcal of prey in model 1 \\
\hline$j_{i}$ & kcal available to a fisher from one individual of prey species $i$ \\
\hline & Maximum kcal of prey a fisher can handle in one unit of time \\
\hline$K_{1}$ & Carrying capacity for prey species 1 \\
\hline$r$. & Fisher per capita reproduction rate \\
\hline & Fisher maximum per capita reproduction rate \\
\hline$V_{T}(t)$ & Total kcal available to fishers from populations of all prey species at time $t$ \\
\hline & $\begin{array}{l}\text { Proportionality constant relating the difference between average and maximum pre- } \\
\text { dation rates to change in predation rate in model } 5\end{array}$ \\
\hline$z$ & $\begin{array}{l}\text { Proportionality constant relating the difference between average and maximum pre- } \\
\text { dation rates to change in predation rate in model } 4\end{array}$ \\
\hline
\end{tabular}

Model 3.-

$$
\begin{aligned}
& V(t+1)=V(t)\left[1+a-\frac{a V(t)}{K}\right]-\frac{k P(t)}{j}\left[\frac{j V(t)}{D+j V(t)}\right] \\
& P(t+1)=P(t)\left[1+r-\frac{r P(t)}{b j V(t)}\right] .
\end{aligned}
$$

Prey mortality in this model is taken from Holling (1965). Predator population dynamics are modeled as in model 2.

Model 4.-

$$
\begin{aligned}
& V(t+1)=V(t)\left[1+a-\frac{a V(t)}{K}\right]-\frac{k P(t)}{j}\{1-\exp [-z j V(t)]\}, \\
& P(t+1)=P(t)+P(t) r_{m}\{1-\exp [-z j V(t)]\}-P(t) \exp [-z j V(t)] .
\end{aligned}
$$

Prey mortality in this model is taken from Ivlev (1961). Because reproduction and mortality of predators are strongly linked to the number of prey killed, I have modeled reproduction rate per predator to be proportional to predation rate divided by maximum predation rate, or

$$
\begin{aligned}
& \begin{array}{l}
\text { reproduction } \\
\text { rate per } \\
\text { predator }
\end{array}=r_{m} \frac{k\{1-\exp [-z j V(t)]\}}{k}=r_{m}\{1-\exp [-z j V(t)]\} \text {. }
\end{aligned}
$$


Also, predator mortality is proportional to the number of unkilled prey per unit time divided by the maximum predation rate, or

$$
\begin{aligned}
& \text { mortality } \\
& \text { rate per } \\
& \text { predator }
\end{aligned}=\frac{k-k\{1-\exp [-z j V(t)]\}}{k}=\exp [-z j V(t)] .
$$

Model 5.-

$$
\begin{aligned}
& V(t+1)=V(t) 1+a-\frac{a V(t)}{K}-\frac{k P(t)}{j}\left[1-\exp \frac{-y j V(t)}{P(t)}\right] \\
& P(t+1)=P(t)+P(t) r_{m}\left[1-\exp \frac{-y j V(t)}{P(t)}\right]-P(t) \exp \left[\frac{-y j V(t)}{P(t)}\right] .
\end{aligned}
$$

Prey mortality in this model is taken from Watt (1959). Predator population change has been modeled as in model 4 except that Watt's expression for prey mortality has been used instead of Ivlev's.

To make models 1-5 one-predator-three-prey community models, snowshoe hares and deer carrion must be added. Because none of the prey compete with each other, hares and deer carrion can be added to the models as follows. The porcupine will be prey 1, the snowshoe hare prey 2 and deer carrion prey 3 . Parameters in the models will have the appropriate subscripts.

Snowshoe hares are the classical example of a species with cyclic population size. Fishers are known to cycle in response to hare population cycles (Bulmer $1974,1975)$. However, it is unlikely that fishers have a significant effect on hare population dynamics because of low fisher populations compared to other predator populations and because hares are known to cycle in the absence of predators (see Archibald 1977; Keith and Windberg 1978). Consequently, hares can be modeled as a neutrally stable population unaffected by the fisher population. I modeled the hare population to have an equilibrium population density equal to the median population density found by Green and Evans $(1940 a, 1940 b, 1940 c)$ and to cycle like a sine wave when perturbed from equilibrium. Thus,

$$
V_{2}(t)=H^{\prime} \sin [36(t+f)]+\bar{H},
$$

where $V_{2}(t)$ is the hare population at time $t, \bar{H}+H^{\prime}$ is the maximum hare population size, $\bar{H}-H^{\prime}$ is the minimum population size, and the integer $f(0 \leqslant f<$ 10) determines the phase of the function. Using $36 t$ gives the population. a $10 \mathrm{yr}$ cycle.

The major sources of deer carrion are car-killed, starved, and hunter-killed deer. Deer carrion has density-dependent removal, but new carcasses are added to the system at a constant rate independent of the number of carcasses already present. Deer carrion removal by fishers will be related to the number of carcasses and fishers, just as porcupine mortality is related to porcupine and fisher populations. Therefore, deer carrion removal can be modeled the same as porcupine mortality in models $1-5$.

In one-predator-three-prey models, total predation by fishers is determined by 
the total kilocalories in all prey populations (i.e., no switching; Murdoch and Oaten 1975). Predation on any one species will be proportional to its percentage of the total prey kilocalories. This assumption explains why models $1-5$ were originally presented with prey in kilocalorie units. Consequently, in one-predator-threeprey models, predation on porcupines and deer carrion will be determined as:

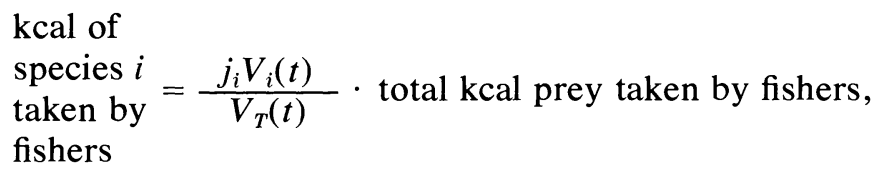

where $V_{i}(t)$ is either $V_{1}(t)$ or $V_{3}(t)$ and $V_{T}(t)$ is the total kcal of prey at time $t: V_{T}(t)$ $=j_{1} V_{1}(t)+j_{2} V_{2}(t)+j_{3} V_{3}(t)$. As an example, in model 2

$$
\begin{aligned}
& V_{1}(t+1)=V_{1}(t)\left[1+a_{1} \frac{a_{1} V_{1}(t)}{K_{1}}\right]-\frac{w P(t)}{j_{1}}\left[V_{T}(t)\right]^{1 / 2}\left[\frac{j_{1} V_{1}(t)}{V_{T}(t)}\right], \\
& V_{3}(t+1)=V_{3}(t)+a_{3}-\frac{w P(t)}{j_{3}}\left[V_{T}(t)\right]^{1 / 2}\left[\frac{j_{3} V_{3}(t)}{V_{T}(t)}\right] .
\end{aligned}
$$

Predator population dynamics are determined by total kilocalories in the prey populations, $V_{T}(t)$, in all models.

\section{RESULTS}

The equilibria for the five one-predator-one-prey model communities are given in table 2.

For the parameter values calculated by Powell (1977) all models are stable for both one prey and three prey. Table 3 shows the calculated parameter values, the equilibria, and the eigenvalues $(\lambda)$ for the five one-predator-one-prey models. Following perturbation models 1 and 2 return to equilibrium with damped oscillations, whereas models 3-5 return asymptotically. Equilibria and eigenvalues for the one-predator-three-prey models could not be calculated because of the complexity of the four simultaneous equations in four variables which needed to be solved. However, using the calculated parameter values in table 3 , the signs for the five one-predator-three-prey community matrices $(A)$ are (the fisher is species 4):

$$
A=\left(\begin{array}{cccc}
- & + & + & - \\
0 & 0 & 0 & 0 \\
+ & + & - & - \\
+ & + & + & -
\end{array}\right) .
$$

Computer simulations of the one-predator-three-prey model communities resemble stable limit cycles.

Sensitivity analysis results are shown in table 3 . Table 4 shows the ranges of oscillations of fishers, porcupines, snowshoe hares, and deer carrion found by computer simulation of models $1-5$ with the parameter values given in table 3 .

Porcupine population size from 1962 to 1976 in ONF is shown in figure 1. The 


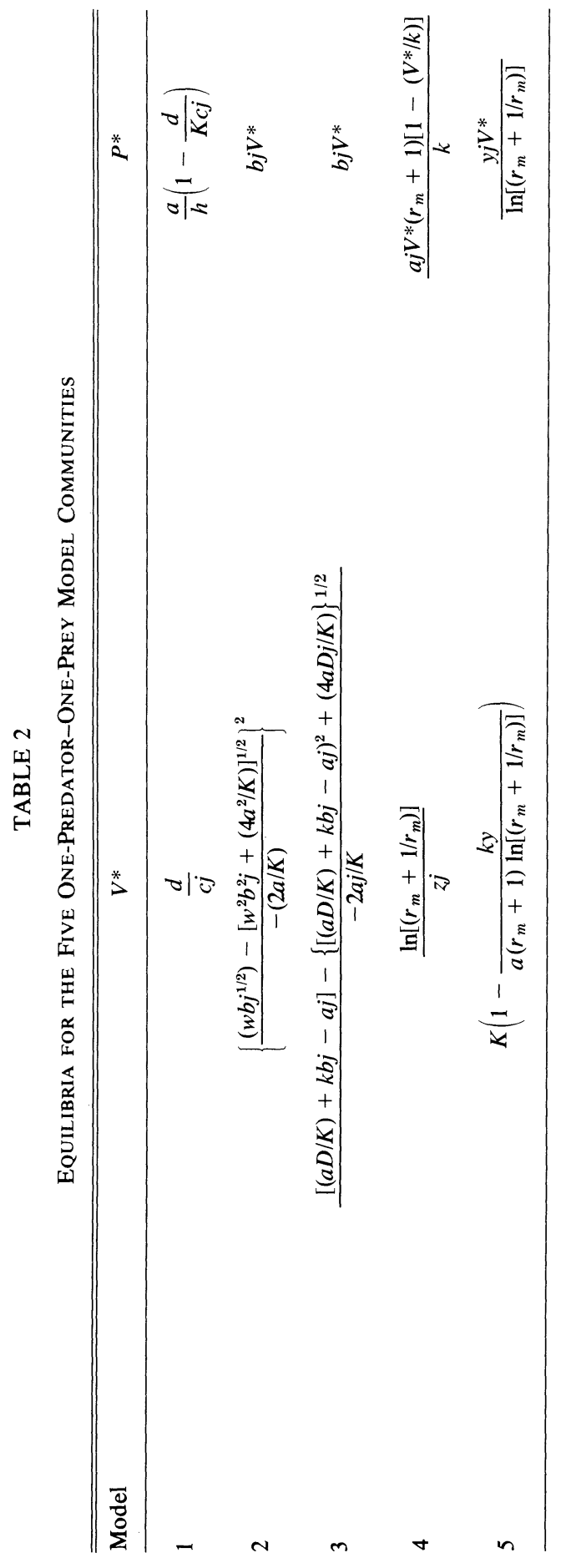


TABLE 3

Calculated Parameter Values and Sensitivity ANALYSIS FOR PARAMETERS IN MODELS 1-5

\begin{tabular}{|c|c|c|c|c|c|}
\hline \multirow{2}{*}{\multicolumn{2}{|c|}{ MODEL }} & \multirow[b]{2}{*}{ PARAMETER } & \multirow{2}{*}{$\begin{array}{c}\text { Calculated } \\
\text { Value }\end{array}$} & \multicolumn{2}{|c|}{ Parameter Stability Ranges } \\
\hline & & & & 1-Prey & 3-Prey \\
\hline \multirow{9}{*}{\multicolumn{2}{|c|}{1}} & $a_{1}^{*}$ & .35 & $.11-2.9$ & $.16-1.0$ \\
\hline & & $a_{3}$ & .75 & $\ldots$ & $0-40$ \\
\hline & & $K_{1}^{*}$ & 1,100 & $860-3,000$ & $230-1,900$ \\
\hline & & $h^{*}$ & $2.0 \cdot 10^{-2}$ & $0-7.5 \cdot 10^{-2}$ & $0-5.0 \cdot 10^{-2}$ \\
\hline & & $c^{*}$ & $8.5 \cdot 10^{-8}$ & $6.6 \cdot 10^{-8}-2.2 \cdot 10^{-7}$ & $4.1 \cdot 10^{-8}-9.8 \cdot 10^{-8}$ \\
\hline & & $d$ & -.5 & $-.64--.06$ & $-.99--.41$ \\
\hline & & $P(0)^{*}$ & 4.2 & $.50-31$ & $.50-13$ \\
\hline & & $V_{1}(0)^{*}$ & 835 & $210-3,700$ & $1.0-2,200$ \\
\hline & & $\lambda$ & $-.132 \pm .157 i$ & (2) & $\ldots$ \\
\hline \multirow{9}{*}{\multicolumn{2}{|c|}{2}} & $a_{1}$ & .35 & $.052-2.4$ & $.059-2.6$ \\
\hline & & $a_{3}$ & .75 & $\ldots$ & -950 \\
\hline & & $K_{1}$ & 1,100 & 270-no high & 200-no high \\
\hline & & $w^{*}$ & 80 & $0-290$ & $0-240$ \\
\hline & & $b$ & $7.5 \cdot 10^{-7}$ & $2.4 \cdot 10^{-7}-2.2 \cdot 10^{-6}$ & $2.3 \cdot 10^{-7}-2.2 \cdot 10^{-6}$ \\
\hline & & $r^{*}$ & 1.5 & $.01-2.8$ & $.01-2.4$ \\
\hline & & $P(0)$ & 3.6 & $.50-5.7$ & $.50-14$ \\
\hline & & $V_{1}(0)$ & 685 & $480-2,900$ & $1.0-3,900$ \\
\hline & & $\lambda$ & $-.450,-.188$ & $\ldots$ & $\ldots$ \\
\hline \multirow{10}{*}{\multicolumn{2}{|c|}{3}} & $a_{1}$ & .35 & $.10-2.5$ & $.23-2.8$ \\
\hline & & $a_{3}$ & .75 & $\ldots$ & 0-97 \\
\hline & & $K_{1}$ & 1,100 & 560-no high & 110-no high \\
\hline & & $k$ & $8.0 \cdot 10^{5}$ & $0-1.2 \cdot 10^{6}$ & $0-1.2 \cdot 10^{6}$ \\
\hline & & $D^{*}$ & $4.0 \cdot 10^{6}$ & $9.5 \cdot 10^{5}-$ no high & $1.4 \cdot 10^{6}-$ no high \\
\hline & & $b^{*}$ & $7.5 \cdot 10^{-7}$ & $5.5 \cdot 10^{-7}-1.4 \cdot 10^{-6}$ & $4.7 \cdot 10^{-7}-1.1 \cdot 10^{-6}$ \\
\hline & & $r^{*}$ & 1.5 & $.01-2.9$ & $.01-2.1$ \\
\hline & & $P(0)$ & 3.4 & $.50-5.5$ & $.50-11$ \\
\hline & & $V_{1}(0)$ & 645 & $590-1,300$ & $560-3,600$ \\
\hline & & $\lambda$ & $-.351 \pm-.270 i$ & & $\ldots$ \\
\hline \multirow{9}{*}{\multicolumn{2}{|c|}{4}} & $a_{1}$ & .35 & $.23-2.7$ & $.18-3.1$ \\
\hline & & $a_{3}$ & .75 & $\ldots$ & $0-100$ \\
\hline & & $K_{1}$ & 1,100 & $1,000-1,300$ & $750-1,400$ \\
\hline & & $k$ & $8.0 \cdot 10^{5}$ & $0-1.2 \cdot 10^{6}$ & $0-1.2 \cdot 10^{6}$ \\
\hline & & $z^{*}$ & $6.0 \cdot 10^{-8}$ & $5.5 \cdot 10^{-8}-1.1 \cdot 10^{-7}$ & $4.1 \cdot 10^{-8}-6.1 \cdot 10^{-8}$ \\
\hline & & $r_{m} *$ & 2.0 & $1.9-4.1$ & $1.3-2.2$ \\
\hline & & $P(0)$ & 1.1 & $.50-6.6$ & $.50-7.0$ \\
\hline & & $V_{1}(0)$ & 960 & $610-3,500$ & $150-1,600$ \\
\hline & & $\lambda$ & $-.148 \pm .114 i$ & $\ldots$ & $\ldots$ \\
\hline \multirow{9}{*}{\multicolumn{2}{|c|}{5}} & $a_{1}$ & .35 & $.25-3.1$ & $.18-3.2$ \\
\hline & & $a_{3}$ & .75 & $\ldots$ & 0-no high \\
\hline & & $K_{1}$ & 1,100 & 235-no high & 96-no high \\
\hline & & $k$ & $8.0 \cdot 10^{5}$ & $0-1.1 \cdot 10^{6}$ & $0-1.4 \cdot 10^{6}$ \\
\hline & & $y$ & $3.5 \cdot 10^{-7}$ & $8.1 \cdot 10^{-8}-5.0 \cdot 10^{-7}$ & $6.4 \cdot 10^{-8}-6.1 \cdot 10^{-7}$ \\
\hline & & $r_{m}$ & 2.0 & $.20-32$ & 0-no high \\
\hline & & $P(0)$ & 2.3 & $.50-$ no high & $.50-$ no high \\
\hline & & $V_{1}(0)$ & 375 & $77-3,700$ & $49-3,900$ \\
\hline & & $\lambda$ & $-.767,-.051$ & $\ldots$ & $\ldots$ \\
\hline \multirow{3}{*}{\multicolumn{2}{|c|}{$1-5$}} & $j_{1}$ & 7,054 & $\ldots$ & $\cdots$ \\
\hline & & $j_{2}$ & 1,607 & $\ldots$ & $\ldots$ \\
\hline & & $j_{3}$ & 16,220 & $\ldots$ & $\ldots$ \\
\hline
\end{tabular}

Note.-The values for $P(0), V_{1}(0)$, and $\lambda$ under calculated values are calculated equilibrium values and eigenvalues for one-predator-one-prey forms of the models. Instability is defined as $P(t)<$ .50 or $V_{1}<1.0$ when $t \leqslant 100 \mathrm{yr}$. Only one parameter was tested at a time; other parameters were held at calculated values.

*Those parameters for which the stability range is larger for a given model in its one-predator-oneprey form than in its one-predator-three-prey form. 
TABLE 4

Range of Population Cycles for Fishers $(P)$, Porcupines $\left(V_{1}\right)$, Snowshoe Hares $\left(V_{2}\right)$ and Dead Deer $\left(V_{3}\right)$ In Models $1-5$

\begin{tabular}{|c|c|c|c|c|c|}
\hline & Model 1 & Model 2 & Model 3 & Model 4 & Model 5 \\
\hline$P$ & $1.4-10.2$ & $3.7-9.9$ & $1.3-7.3$ & $2.1-8.9$ & $3.2-10.0$ \\
\hline$V_{1} \ldots \ldots$ & $200-720$ & $555-665$ & $145-234$ & $525-785$ & $350-375$ \\
\hline$V_{2} \ldots$ & $480-5,305$ & $480-5,305$ & $480-5,305$ & $480-5,305$ & $480-5,305$ \\
\hline$V_{3} \ldots$ & $2.0-6.0$ & $4.4-5.2$ & $2.1-3.5$ & $4.2-6.2$ & $3.2-3.4$ \\
\hline
\end{tabular}

Note.-Parameter values are as in table 3 . Populations are per $100 \mathrm{~km}^{2}$.

fisher population in 1962 in the same sample study area was about one fisher per $100 \mathrm{~km}^{2}$ (Irvine et al. 1962, 1964) and in 1972 to 1976 ranged from four to eight fishers per $100 \mathrm{~km}^{2}$ (Powell 1977).

For both one-predator-one-prey and one-predator-three-prey model communities, large perturbations (including fisher and porcupine population sizes similar to those in 1962 in ONF) do not lead to values of predator or prey which imply extinction in the real world. In all models, $V_{1}(0)$ must be much greater than $K_{1}$ for extinction of porcupines or fishers to occur, and $P(0)$ has no lower limit except that imposed by extinction.

\section{DISCUSSION}

Because the fossil and subfossil records do not give concrete evidence of community stability, it would not have been surprising if at least one of the models had predicted extinction of either fishers or porcupines. However, the stable predator-prey relationship in all model communities makes the interpretation robust that fishers and porcupines have had a stable relationship over evolutionary time. What are some of the sources of this stability?

Murdoch and Oaten (1975) found that ( $a$ ) density-dependent prey reproduction, (b) a prey refuge, $(c)$ an invulnerable prey age class, and (d) habitat spatial heterogeneity had stabilizing effects on the neutrally stable Lotka-Volterra predator-prey model. For a predator with alternative prey, stability was enhanced if the predator "switched." Maynard Smith and Slatkin (1973) found that a different one-predator-one-prey model was stabilized when differential hunting abilities for predators were incorporated into the model.

Of these potentially stabilizing factors, only density-dependent reproduction of porcupines was incorporated into the models investigated here. There is conflicting evidence as to whether porcupines have an invulnerable class. Coulter (1966) believed that large porcupines are safe from fisher predation, but Earle (1978) and Powell and Brander (1977) gave evidence that porcupines of all sizes are subject to fisher predation. Porcupines do not have a refuge, and there is no spatial heterogeneity in the habitat as considered by Murdoch and Oaten (1975). There is no evidence concerning whether fishers switch between prey in response to changes in prey density. Furthermore, the large differences in energy available and risk 
between porcupines and other prey (Powell 1977, 1979) would make switching difficult to recognize and interpret. There is some evidence that young fishers do not have the hunting ability of old fishers (Coulter 1966; Kelly 1977; Powell 1977).

May (1973) showed that, contrary to popular belief, adding species to a community has a destabilizing effect on almost all model communities for a broad class of models. However, with the rather different model communities investigated here this was not the case: Increased number of species did not lead to community instability. Porcupine and fisher population sizes in table 4 more closely resemble population estimates than the equilibria in table 3 . The eigenvalues show that the five one-predator-one-prey model communities have neighborhood stability; unfortunately the eigenvalues for the one-predator-three-prey communities could not be calculated for comparison. Sensitivity analysis results can be compared. Over all five models, there are 36 parameters which can be compared between the one-prey and three-prey communities. Of those parameters, almost two-thirds have larger stability ranges in the three-prey communities than in the one-prey communities, and a further one-fifth are not contained in the one-prey community stability ranges. Taken as a group, the three-prey model predator-prey communities are more stable than the one-prey communities. Only in model 1 were more than one-half the stability ranges smaller for the three-prey community, while in model 5 all ranges were larger for three-prey. Taken individually, only in model 1 was the one-prey community more stable than the three-prey community.

It was expected that computer simulation of the one-predator-three-prey model communities should resemble stable limit cycles. The community matrices of these models imply that real communities described by the models should have qualitative stability and that the cycling hare population would drive stable populations into stable cycles. The necessary and sufficient stability criteria for an $m \times m$ matrix $(A)$ for which only the signs $(+, 0,-)$ of the elements are known follow (May 1973).

1. $\alpha_{i i} \leqslant 0$, for all $i$.

2. $\alpha_{i i} \neq 0$, for at least one $i$.

3. $\alpha_{i j} \alpha_{j i} \leqslant 0$, for all $i \neq j$.

4. For any sequence of three or more indices, $i, j, k, \ldots, q, r$ (with $i \neq j \neq k \neq$ $\ldots \neq q \neq r$ ), the product $\alpha_{i j} \alpha_{j k} \ldots \alpha_{q r} \alpha_{r i}=0$.

5. $\operatorname{det} \mathrm{A} \neq 0$.

For the community matrices of models $1-5$ with three prey, criteria 1,2 , and 4 are immediately met. Values of $\alpha_{13}$ and $\alpha_{31}$ (the effect of carrion on porcupines and vice versa) are so small that the product $\alpha_{13} \alpha_{31}$ is essentially 0 , satisfying criterion 3. Also, in reality $\alpha_{24}$ would be negative because the small effect fishers do have on the hares is negative, satisfying criterion 5. This implies that the real communities described by this set of matrices should have qualitative stability. The community matrices of the model communities investigated here do not depart far enough from criteria 3 and 5 to cause the computer simulations to depart from apparent limit cycles.

May (1973) showed that competition is destabilizing in model communities. The signs of the community matrix for a one-predator-three-prey community where 
the prey do not compete and all have at least partially density-dependent reproduction are

$$
A^{\prime}=\left(\begin{array}{cccc}
- & 0 & 0 & - \\
0 & - & 0 & - \\
0 & 0 & - & - \\
+ & + & + & -
\end{array}\right)
$$

This matrix satisfies all five criteria for qualitative stability. The signs of the community matrix for a one-predator-three-prey community where the prey do compete and all have at least partially density-dependent reproduction are

$$
A^{\prime \prime}=\left(\begin{array}{cccc}
- & - & - & - \\
- & - & - & - \\
- & - & - & - \\
+ & + & + & -
\end{array}\right) \text {. }
$$

There is no way that this matrix can meet criteria 3 and 4 , so real communities described by this matrix cannot be qualitatively stable. Competition between prey is responsible for the loss of qualitative stability in such communities. This means that these communities can only be stable for particular magnitudes of the elements in the community matrix.

One important reason that the one-predator-three-prey model communities presented here are stable is that the prey species do not compete. Even though the construction of the communities was based on one real community, the model types were diverse and the community matrices general, making this conclusion applicable to a wide range of communities. No competition or limited competition appears to be common in real communities. This may be due to group selection for stable communities (Gilpin 1975), or more likely due to reduced competition because of environmental variability (Wiens 1977). Low competition between prey species may thus be a stabilizing factor for many predator-prey communities. If interspecies interactions besides competition (e.g., predation) occur in a community, competition may be of minor importance to community stability. This is not to say that competition is not important to prey species. However, in a predator-prey community one must evaluate the importance of competition between prey relative to the importance of predation pressure and prey food, habitat, and temporal specificity.

\section{SUMMARY}

May (1973) showed that complex model communities tend to be less stable than simple model communities, but noted that complex real communities do appear to be stable. Therefore research should seek to elucidate what kinds of complexities are stabilizing.

Five model predator-prey communities, developed from the literature and based on the fisher-porcupine-snowshoe hare-deer carrion predator-prey com- 
munity in Upper Peninsula Michigan, show stability in both one-predator-oneprey and one-predator-three-prey forms. In addition, most of the one-predatorthree-prey communities are more stable than one-predator-one-prey communities. One major reason for this stability of the more complex communities is believed to be lack of competition between the prey. Lack of competition between prey is believed to be reasonably widespread in predator-prey communities.

\section{ACKNOWLEDGMENTS}

Monte Lloyd provided impetus for the initiation of this work and gave many helpful criticisms along the way. He, Ross Kiester, Steve Arnold, Dave Mech, George Rabb, and Ron Alderfer commented on early drafts of the paper. Stuart Altmann provided the WANG $720 \mathrm{C}$.

\section{LITERATURE CITED}

Anderson, E. 1970. Quaternary evolution of the Genus Martes (Carnivora, Mustelidae). Acta Zool. Fenn. 130.

Archibald, H. L. 1977. Is the 10-year wildlife cycle induced by a lunar cycle? Wildl. Soc. Bull. 5:126-129.

Brander, R. B., and D. J. Books. 1973. Return of the fisher. Nat. Hist. 82(1):52-57.

Bulmer, M. G. 1974. A statistical analysis of the 10-year cycle in Canada. J. Anim. Ecol. 43:701-718. 1975. Phase relations in the ten-year cycle. J. Anim. Ecol. 44:609-622.

Coulter, M. W. 1966. Ecology and management of fishers in Maine. Ph.D. thesis. State University College of Forestry at Syracuse University.

Earle, R. D. 1978. The fisher-porcupine relationship in Upper Michigan. M.S. thesis. Michigan Technological University.

Gause, G. F. 1934. The struggle for existence. Williams \& Wilkins, Baltimore.

Gilpin, M. E. 1975. Group selection in predator-prey communities. Princeton University Press, Princeton, N.J.

Green, R. G., and C. A. Evans. 1940a. Studies of a population cycle of snowshoe hares on the Lake Alexander area. I. Gross annual census. J. Wildl. Manage. 4:221-236.

$1940 \mathrm{~b}$. Studies of a population cycle of snowshoe hares on the Lake Alexander area. II. Mortality according to age groups and season. J. Wildl. Manage. 4:267-278.

$1940 \mathrm{c}$. Studies of a population cycle of snowshoe hares on the Lake Alexander area. III. Effect of the reproduction and mortality of young hares on the cycle. J. Wildl. Manage. 4:347-358.

Hibbard, C. W. 1970. Pleistocene mammalian local faunas from the Great Plains and central lowland provinces of the United States. Pages 395-433 in W. Dort, Jr., and J. K. Jones, Jr., eds. Pleistocene and recent environments of the central Great Plains. Univ. Kans. Dep. Geol. Spec. Publ., no. 3.

Holling, C. S. 1965. The functional response of predators to prey density and its role in mimicry and population regulation. Mem. Entomol. Soc. Can. 45:1-60.

Irvine, G. W., B. J. Bradle, and L. T. Magnus. 1962. The restocking of fisher in lake states forests. Paper presented at the 24th Midwest Fish \& Wildlife Conference, Des Moines, Iowa. December 5.

Irvine, G. W., and R. B. Brander. 1971. Progress report on a fisher-porcupine study on the Ottawa National Forest. Available from: North Central Forest Experiment Station, Forest Service, U.S. Department of Agriculture.

Irvine, G. W., L. T. Magnus, and B. J. Bradle. 1964. The restocking of fisher in lake states forests. Trans. N. Am. Wildl. Nat. Resour. Conf. 29:307-315.

Ivlev, V. S. 1961. Experimental ecology of feeding in fishes. Yale University Press, New Haven, Conn. 
Keith, L. B., and L. A. Windberg. 1978. A demographic analysis of the snowshoe hare cycle. Wildl. Monogr. no. 58.

Kelly, G. M. 1977. Fisher (Martes pennanti) biology in the White Mountain National Forest and adjacent areas. Ph.D. thesis. University of Massachusetts, Amherst.

Leslie, P. H. 1948. Some further notes on the use of matrices in population mathematics. Biometrica 35:213-245.

May, R. M. 1973. Stability and complexity in model ecosystems. Princeton University Press, Princeton, N.J.

Maynard Smith, J., and M. Slatkin. 1973. The stability of predator-prey systems. Ecology 54:384-391.

McNaughton, S. J. 1977. Diversity and stability of ecological communities: a comment on the role of empiricism. Am. Nat. 111:515-525.

Murdoch, W. W., and A. Oaten. 1975. Predation and population stability. Adv. Ecol. Res. 9:2-125.

Powell, R. A. 1976. Compact carnivore. Anim. Kingdom 79(6):12-19.

1977. Hunting behavior, ecological energetics and predator-prey community stability of the fisher (Martes pennanti). Ph.D. thesis. University of Chicago.

1978. A comparison of fisher and weasel hunting behavior. Carnivore 1(1):28-34.

1979. Ecological energetics and foraging strategies of the fisher (Martes pennanti). J. Anim. Ecol. 48:195-212.

, and R. B. Brander. 1977. Adaptations of fishers and porcupines to their predator prey system. Pages 45-53 in R. L. Phillips and C. Jonkel, eds. Proceedings of the 1975 predator symposium. Montana Forestry \& Conservation Experimental Station, University of Montana, Missoula.

Rosenzweig, M. L. 1971. Paradox of enrichment: destabilization of exploitation ecosystems. Science 171:385-387.

Watt, K. E. F. 1959. A mathematical model for the effect of density of attacked and attacking species on the number attacked. Can. Entomol. 91:129-144.

Wiens, J. A. 1977. On competition and variable environments. Am. Sci. 65:590-597. 